\title{
PERCEPÇÃO DE MÃES ADOLESCENTES ACERCA DA PARTICIPAÇÃo PATERNA \\ NA GRAVIDEZ, NASCIMENTO E CRIAÇÃO DO FILHO
}

\author{
ADOLESCENTE MOTHER'S VIEW ON FATHER'S PARTICIPATION IN THE \\ PREGNANCY, BIRTH, AND RAISING OF A CHILD
}

\section{LA PERCEPCIÓN DE MADRES ADOLESCENTES ACERCA DE LA PARTICIPATION DEL PADRE EN EL EMBARAZO, NACIMIENTO Y CRIACIÓN DEL HIJO}

\author{
Silmara Delgado Gonçalves* \\ Cristina Maria Garcia de Lima Parada** \\ Neide Marina Feijó Bertoncello**
}

Gonçalves SD, Parada CMGL, Bertoncello NMF. Percepção de mães adolescentes acerca da participação paterna na gravidez, nascimento e criação do filho. Rev Esc Enferm USP 2001; 35(4): 406-13.

\begin{abstract}
RESUMO
A participação paterna na gravidez de adolescentes ainda é pouco discutida, embora a ausência do companheiro seja apontada como um dos problemas sociais dela decorrente. Esta investigação, de cunho qualitativo, teve por objetivo descrever como se dá a participação do pai do bebê durante a gestação, nacimento e criação do filho nos primeiros meses de vida, na perspectiva de adolescentes que passaram pela experiência de engravidar e ter um filho. Na sistematização dos dados, os mesmos foram agrupados em duas categorias: vivenciando a gravidez e valorizando a presença e participação do companheiro/pai.
\end{abstract}

PALAVRAS-CHAVE: Gravidez. Adolescente. Gravidez na adolescência.

\begin{abstract}
Paternal participation in adolescents' pregnancy is little discussed. Although the absence of the partner is pointed out as one of the problems due to it. This research had the aim to ascertain, under the perspective of mothers who gave birth at an early age, the participation of a father during gestation, birth, and raising of his child in the first months of life. In order to record data, two categories have been devised: experiencing pregnancy and valuing a partner/father 's presence and participation.
\end{abstract}

KEYWORDS: Pregnancy. Adolescent. Pregnancy in adolescence.

\section{RESUMEN}

La participación del padre en el embarazo de adolescentes es poco discutida, aunque la ausencia del compañero sea apuntada como un de los problemas sociales della decorrente. Esta investigación cualitativa, tuve por objetivo describir como fue la participación del padre mientras la gravidez, nascimiento y criación del hijo en los primeros meses de vida, en la perspectiva de las adolescentes que pasaran por la experiencia de embarazar y tener un hijo. En la sistematización de los datos, los mismos fueran agrupados en dos categorias: vivenciando el embarazo y valorizando la presencia y participación del compañero/padre.

PALABRAS-CLAVE: Embarazo. Adolescente. Embarazo en la adolescencia.

\footnotetext{
Enfermeira, bolsista de Iniciação Científica/ PIBIC CNPq durante o Curso de Graduação.

* Enfermeira, Professor Assistente Doutor do Departamento de Enfermagem da Faculdade de Medicina de Botucatu da Universidade Estadual Paulista. Email: cparada@uol.com.br

** Enfermeira, Professor Assistente Doutor do Departamento de Enfermagem da Faculdade de Medicina de Botucatu da Universidade Estadual Paulista. Email: nfeijo@fmb.unesp-br
} 


\section{INTRODUÇÃO}

A definição de adolescente realizada pela Organização Mundial de Saúde (OMS) inclui aspectos biológicos: o indivíduo evolui para a completa maturação sexual; social: o indivíduo vivencia um momento de transição para um estado de relativa independência, e psicológico: os processos psicológicos e as linhas de identificação evoluem da criança para o adulto. A adoção desses critérios, porém, não diminui as dificuldades em se delimitar a faixa etária da adolescência e, por isso, a mesma OMS apresenta uma definição cronológica, propondo que esse período se estenda dos 10 aos 19 anos de idade(1).

A relação entre gravidez e adolescência tem sido estudada de forma intensa nas três últimas décadas. Muitos desses estudos têm sido voltados aos aspectos biológicos e ao desempenho obstétrico das grávidas adolescentes, freqüentemente classificando-as como de alto-risco, devido a maior incidência de patologias na gestação, complicações obstétricas ligadas às variáveis de parto e intercorrências perinatais.

O desejo inconsciente de ficar grávida, demonstrado algumas vezes pelo sentimento contraditório entre o não querer engravidar e a satisfação com a gravidez, a tentativa de melhorar as condições sócio-econômicas e a necessidade não satisfeita de proteção e atenção na infância(2), a vontade de provar que é mulher e de verificar se o "corpo funciona", a necessidade de ter alguém para amar (o filho), a tentativa de conseguir casar com o homem amado, a vontade de contrariar os pais, a busca de uma alternativa para sair de casa, da escola ou da cidade onde mora, a vontade de satisfazer um desejo oculto dos pais e a tentativa de aliviar uma sensação de depressão e isolamento, são apontadas como as causas mais freqüentes da gravidez na adolescência(3).

Quanto aos aspectos sociais da gestante adolescente, tem-se estudado o estado civil, a escolaridade, ocupação e estrutura familiar. Discutese, nestas investigações, a condição social desfavorável destas jovens: ausência de companheiro, uniões informais e instáveis, o que as torna sujeitas a discriminação social e legal (2,4-5) e a baixa escolaridade ou o abandono escolar após a descoberta da gravidez que, por sua vez, faz com que essas adolescentes, ao entrarem no mercado de trabalho, executem uma atividade não qualificada e, conseqüentemente, pior remunerada $(6,7)$

O co-responsável pela gravidez dessas jovens pode ser considerado o grande ausente do processo, ou porque não participa efetivamente das conseqüências do seu ato, ou porque os estudos e estudiosos da gravidez na adolescência não têm demonstrado grande interesse por ele. As poucas referências a esse personagem, quando existem, são sempre indiretas, seja apontando o grande números de mães solteiras, seja referindo-se a sua ausência como um dos fatores que concorrem para a problemática dessa gravidez, ou pelo ceticismo com que os autores vêem os casamentos que ocorrem em função da constatação da gestação, fato comum e fadado ao fracasso, visto que à partir de uma gravidez indesejada são realizados muitos casamentos indesejados(1).

Quando também adolescente, o pai tem menos possibilidades de completar seus estudos e maior possibilidade de desempenhar trabalhos não qualificados, de casar-se prematuramente, de divorciar-se e de ter maior número de filhos. Do ponto de vista emocional, estes rapazes são mais estressados, contribuindo para isso a preocupação com seu futuro profissional, com a saúde da mãe e de seu filho, as dúvidas quanto a sua capacidade de ser pai, quanto a situação econômica presente e futura e relação com a gestante adolescente. Além disso, o pai adolescente sofre uma reação negativa do meio que o rodeia: os serviços de saúde não os incluem nos programas de educação perinatal e os adultos transformam a censura inicial pelo início precoce das relações sexuais em condenação. Ressalta-se, ainda, a necessidade imediata do pai contribuir financeiramente com os custos relativos a atenção médica da mãe e filho, quase sempre sem estar preparado para isso(8).

Muitos jovens, pelo fato de serem pais, sentemse ameaçados, em vias de perder sua independência, tendo que assumir papel de maior vulto e responsabilidade, sem que estejam preparados. Diante desse panorama, muitos deles optam por negar a paternidade do bebê( ${ }^{(9)}$.

$\mathrm{O}$ estreito e satisfatório relacionamento da adolescente grávida com o pai do bebê- reflete positivamente no comportamento afetivo da mãe com a criança. Em seu estudo, a autora apresenta revisão bibliográfica acerca da relação entre mães adolescentes e os pais de seus bebês, apontando que a recusa da paternidade pode repercutir de forma negativa, tornando-se uma importante fonte de estresse para a adolescente. Por outro lado, a aceitação da gravidez e um bom relacionamento entre a adolescente e o pai do bebê, faz com que a mãe se sinta amparada e comece cedo a participar de acompanhamento pré-natal, o que é de grande importância para um periodo perinatal sem complicações. Conclui a autora, que os pais de bebês de mães adolescentes deveriam ser incluidos, de forma apropriada, no contínuo cuidado da mãe e da criança, inclusive para a melhora do relacionamento entre eles ${ }^{(10)}$.

Diante do quadro apresentado e tendo em vista a carência de estudos sobre a participação paterna na gestação de adolescentes, propusemo-nos a estudar esse tema. Nesse sentido, temos como objetivo descrever como se dá a participação do pai do bebê durante a gestação, nascimento e criação do filho nos primeiros meses de vida, na perspectiva de adolescentes que vivenciaram a experiência de engravidar e ter um filho. 


\section{ASPECTOS METODOLÓGICOS}

\section{O Local de Realização do Estudo}

Esta investigação foi realizada no Centro de Saúde Escola (OSE) da Faculdade de Medicina de Botucatu - UNESP, cuja área de abrangência inclui o $2^{\circ}$ subdistrito do municipio de Botucatu - SP, com 36 bairros, e o distrito de Rubião Júnior. Conta com uma população estimada, à partir do CENSO de 1991, de 19413 habitantes, dos quais 3870 (20\%) estão na faixa etária entre 10 e 19 anos, sendo 1933 (49,9\%) homens e 1937 (50,1\%) mulheres.

Até o início deste estudo não existia um ambulatório específico para atendimento às adolescentes grávidas neste Serviço e quanto a saúde da criança, eram desenvolvidas atividades de puericultura, atendimento eventual às crianças doentes, vacinação, ambulatório de aleitamento materno e grupo de cuidados do bebê, atividade educativa dirigida às gestantes no terceiro trimestre de gravidez.

\section{Referencial Teórico-Metodológico}

A participação paterna junto às mães adolescentes, é um fenômeno que não deve ser estudado desvinculado de suas caracteristicas e condicionantes sócio-culturais. Nesse sentido, buscamos contextualizar, relacionar e conhecer as contradições da paternidade na adolescência, sem perder de vista que mães e pais são sujeitos de sua realidade, construindo-a ininterruptamente ao longo do tempo, numa perspectiva histórica e social.

Considerando o fenômeno estudado por essa perspectiva, o caminho metodológico que se mostrou adequado para nortear a pesquisa foi de cunho qualitativo, que, segundo vários autores, é o mais apropriado para analisar os processos históricos, as relações entre individuo e sociedade, entre realidade e sua compreensão pela ciência, apresentando como atributo a possibilidade de explorar com maior profundidade os seus aspectos objetivos e subjetivos".

A pesquisa qualitativa é apropriada para estudar a "questão do significado e da intencionalidade como inerentes aos atos, às relações e às estruturas sociais", dessa forma, julgamos adequado a utilização dessa abordagem no presente estudo, uma vez que está incluso em nosso objetivo a intenção de buscar dados capazes de identificar aspirações, crenças, valores, emoções e significados das ações e ralações humanas ${ }^{(12)}$.

A metodologia qualitativa é adequada quando se considera os entrevistados como sujeitos e se busca conhecer um determinado fenômeno através dos atores sociais e dos sentidos que eles atribuem aos objetos e às ações sociais que desenvolvem ${ }^{(13)}$.

Entendendo a mãe adolescente como sujeito ativo de sua realidade, buscamos apreender a participação paterna no processo de gravidez e primeiros meses da criação do filho, sob o ponto de vista das adolescentes. Para isso, nos propusemos a entrevistar mães atendidas no OSE que, no momento da coleta de dados, tinham idade igual ou inferior a 19 anos.

\section{Coleta de Dados}

Os dados foram colhidos no período de setembro de 1998 a janeiro de 1999, no serviço de saúde anteriormente descrito. Como instrumento para coleta de dados, optamos por utilizar a entrevista semiestruturada, que possibilita, partindo de questões básicas relacionadas aos objetivos do estudo, a ampliação para outras, que surgem à medida que as respostas vão sendo obtidas, permitindo, também, que os entrevistados possam participar da elaboração do conteúdo da pesquisa, sendo que ao mesmo tempo que valoriza o pesquisador, dá a oportunidade para que o informante alcance a liberdade e a espontaneidade necessárias para o enriquecimento da investigação(14).

Na pesquisa qualitativa, a questão do significado e da intencionalidade são centrais e estes são mais facilmente recuperados através do discurso, que por sua vez pode ser obtido com mais naturalidade e clareza nas entrevistas. Neste sentido, a entrevista semi estruturada dá acesso a dados da realidade de caráter subjetivo, como idéias, crenças, maneiras de pensar e atuar, opiniões, sentimentos, conduta ou comportamento e razões conscientes ou inconscientes ${ }^{(12)}$.

Para a realização da entrevista, os objetivos e finalidades do estudo foram apresentados às adolescentes, tendo-se garantido o sigilo no tratamento e divulgação dos dados. Em seguida, solicitamos a informante sua anuência para utilizarmos o gravador. Este estudo foi avaliado e aprovado por Comitê de Ética em Pesquisa.

A qualidade dos dados obtidos, sua adequação aos objetivos estabelecidos e a repetição das falas das adolescentes, fizeram-nos encerrar a coleta de dados após 21 entrevistas. Destacamos que, como tínhamos interesse em colher os dados após o nascimento do bebê, buscamos as adolescentes a serem entrevistadas na área de pediatria do OSE, onde estavam aguardando que seus filhos fossem atendidos.

\section{Análise dos Dados}

As fitas gravadas foram transcritas na íntegra e, após a leitura exaustiva, repetida e atenta das informações obtidas, pudemos estabelecer classificações, agrupando elementos ou aspectos com características comuns ou que mantinham relação entre si, chamadas de estruturas relevantes dos atores sociais, que passamos a chamar de categorias". Trabalhar com categorias significa agrupar elementos, idéias ou expressões em torno de um conceito capaz de abranger tudo isso(15). 
Após esta classificação inicial, procuramos estabelecer articulações entre o conteúdo das falas, o referencial teórico adotado, as características e contexto sócio-familiar das entrevistadas e pais, buscando atender ao objetivo desta investigação.

\section{RESULTADOS E DISCUSSÃO}

Para subsidiar a análise dos dados apresentamos, primeiramente, algumas características que julgamos importantes sobre as próprias adolescestes, sobre os pais de seus filhos e sobre o contexto sóciofamiliar em que vivem.

A idade das adolescentes variou de 15 a.19 anos, havendo um predomínio numérico para a faixa etária entre 15 e 17 anos. A maioria das jovens (59,1\%), não estudava nem exercia atividade remunerada e, quanta ao número de filhos, uma adolescente de 19 anos tinha dois filhos, ambos do mesmo companheiro e as demais tinham apenas um filho. E necessário, então, ponderarmos que nem sempre a gravidez na adolescência é acontecimento único, acidental, na vida de uma jovem, visto que ela pode se repetir.

Pelas informações das mães, todas essas crianças estavam saudáveis, tendo sido citada a ocorrência ocasional de distúrbios respiratórios, como bronquite, pneumonia e gripe.

De acordo com as próprias adolescentes, nenhuma estava grávida no momento da entrevista. Todas gozavam de boa saúde e, para maioria delas, o parto era recente, tendo ocorrido em um periodo igual ou inferior há 6 meses. Uma característica que nos parece importante ressaltar, é que poucas adolescentes estavam trabalhando $(13,6 \%)$ e, portanto, contribuindo financeiramente para o seu sustento e de seus filhos. Isso, no nosso entendimento, evidencia o pouco envolvimento das entrevistadas com os aspectos financeiros de sua realidade concreta, o que nos parece ter relação com a idade dessas jovens e, portanto, com a adolescência. Por outro lado, devemos considerar o problema atual do desemprego, especialmente quando a mão-de-obra é pouco especializada, situação das adolescentes deste estudo. Além disso, a dificuldade em obter creche ou mesmo alguma pessoa da família para cuidar da criança em sua ausência, fato relatado pelas adolescentes, também as impediam de exercer qualquer atividade fora de casa.

Com relação aos pais, as informações obtidas revelaram que, apesar da grande variação etária, visto que os pais tinham entre 16 e 42 anos, a faixa de 18 a 22 anos foi a mais freqüente, aí situando-se mais da metade dos pais $(59,1 \%)$. Com relação a escolaridade, pode-se dizer ser baixa, já que a maior parte deles $(63,6 \%)$ tinha cursado até o ensino fundamental. Ressaltamos que três pais ainda estavam estudando e aqueles com escolaridade igual ou acima ao ensino médio não possuiam renda, quando da realização das entrevistas.

Com tal escolaridade, era de se esperar que os pais desenvolvessem atividades profissionais pouco especializadas e mal remuneradas. Isso confirmou-se quando investigamos suas atividades profissionais e renda mensal, já que a maior parte deles $(63,6 \%)$ não tinha qualquer atividade remunerada ou recebia até três salários mínimos, sendo a maior renda citada de pouco mais de 7 salários mínimos.

Quanto as atividades profissionais remuneradas, desenvolvidas por pouco mais da metade desses pais, estavam distribuidas em diversos grupos, com destaque para aquele que incluia os pedreiros, serventes de pedreiro, serralheiros e ajudantes de serralheiro.

Como poucas adolescentes trabalhavam, e os pais que desenvolviam alguma atividade remunerada tinham renda baixa, era de se esperar que os mesmos recebessem ajuda da família. Isso ficou claro quando indagamos a respeito da união e moradia: a grande maioria das entrevistadas $(81,8 \%)$ mantinha um relacionamento estável com o pai de seus filhos e, destas, 83,3\%, moravam com o companheiro. O local de moradia, entretanto, demonstrou o auxílio da família, já que mais da metade dos casais $(53,3 \%)$ morava com os pais, quer fossem dele ou dela. $\mathrm{O}$ apoio familiar também estava presente entre os casais que mantinham o relacionamento, embora morassem separados, cada um com seus pais, e entre as adolescentes que estavam sozinhas.

Ao analisarmos a situação descrita, devemos ponderar como problemas financeiros, dentre outros sócio-econômicos, podem dificultar, ou até mesmo inviabilizar, que a mãe adolescente e pai de seu filho, na medida em que decidam manter o relacionamento, construam seu lar independentemente dos familiares. Parece-nos claro que, freqüentemente, mantém-se a dependência financeira e da estrutura familiar já estabelecida.

É importante ressaltarmos que apenas uma, entre as adolescentes que estavam sozinhas, referiu que o pai do bebê trabalhava. Assim, problemas financeiros podem estar contribuindo de forma importante para o final da relação, já que isso ocorreu no momento em que a gravidez foi descoberta e, certamente, da mesma decorrem gastos que o pai pode não estar preparado para assumir.

Entre as adolescentes que não mantinham, no momento da entrevista, qualquer relacionamento com o pai de seu filho, todas continuavam sozinhas e a idade dos filhos era, na maior parte dos casos, pequena: ao redor de um mês de idade. Ao investigarmos o tempo de união desses casais antes da gravidez, verificamos que o tempo de namoro variou de 1 a 24 meses, o que nos sugere que, para este grupo, o tempo de namoro prévio não garantiu 
que o casal se mantivesse unido. Alguns dos depoimentos obtidos nos fazem pensar que, a partir da constatação da gravidez, surgem motivos para o rompimento, conforme podemos observar nos seguintes depoimentos:

\section{" Na hora (que ele soube) disse: tira,} vamos tirar. Ai eu falei assim: não."

"Ele falou que não era dele... Falou que não ia assumi, que o filho não era dele."

\section{" (Ele) disse que não era dele. Ele não quis} assumi a criança."

Entre as adolescentes que mantinham o relacionamento com o pai do bebê, o tempo de namoro foi bastante variado: para algumas, apenas alguns dias e, para outras, mais de 4 anos. Assim, á manutenção da união do casal após a notícia da gravidez, segundo os depoimentos colhidos, não nos pareceu estar relacionada com o tempo de namoro prévio a ela. Para esses casais, o tempo de união, após o casamento ou decisão de morar juntos estava, em geral, entre 6 e 24 meses.

Quando perguntamos às adolescentes como era a relação com o pai do bebê antes da gravidez, todas responderam, direta ou indiretamente, que era boa, como demonstram as falas a seguir:

\section{"Ah, ele sempre cuidou de mim."}

"Ah, ele me tratava super bem, nada de discussão. Até agora nada de briga..."

"A gente vive bem. A gente nunca brigou."

"Sempre foi boa, nunca teve nada de mal."

Aspectos positivos da relação, antes da gravidez, foram apontados mesmo pelas adolescentes que, no momento da entrevista, estavam sozinhas:

"Antes (da gravidez) era as mil maravilhas."

"Bom, no começo (a relação) era boa, a gente namorava, a gente se dava bem..."

Pelo exposto, fica claro que, para as adolescentes, a relação antes da descoberta da gravidez era boa. Entretanto, a partir deste acontecimento, muitas vezes não planejado de forma consciente e madura, tal relação evoluiu das mais diferentes formas: algumas vezes, com rompimento: " ...Ai passou um mês, depois que eu fiquei grávida, ai eu terminei. Pra ele não ficar no meu ouvido pedindo toda vez pra eu tirá. " e, outras vezes, maior aproximação: " ...Ele falou que tudo que ele queria era um filho... que logo a gente casasse..."

Neste contexto e com as características que priorizamos apresentar, as adolescentes entrevistadas vivenciaram todo processo da gravidez, parto e criação dos filhos, até então. Apresentamos, a seguir, as duas categorias que contém sua percepção a respeito da participação dos pais de seus filhos neste processo.
A primeira categoria, vivenciando a gravidez, aborda desde a fase inicial de descoberta da gravidez, com a subcategoria e agora..?, o relacionamento no período da gravidez e o envolvimento paterno com a gravidez, através da participação nas consultas de prénatal. A segunda categoria, valorizando a presença e participação do companheiro/pai, inclui três momentos: o parto, o primeiro contato do pai com o bebê e sua participação após o parto.

\section{Vivenciando a Gravidez}

E agora...? A notícia da gravidez causou diferentes reações nos pais, como a rejeição: " (ele fez) a maior pressão na minha cabeça de pedir pra eu tirar"; resignação: "ele no começo não queria não, ficava xingando... falava que não queria a criança, que eu tinha que tirá. Aí foi e começou a acostumá" ou alegria: " ... ele ficou feliz...ele sempre falava pra mim que queria, né...ah, ele sempre quis". Embora não houvesse rejeição à gravidez em muitos casos, alguns sentimentos contraditórios apareceram, como medo e susto seguidos de alegria e aceitação: " ele ficou com medo do meu pai...ele gostou...depois ele gostou..." ou "ele levou um susto...(ele) gostou...eu vi, né, que ele ficou contente". Podemos apontar, pela análise dos dados deste estudo, que a aceitação ou não da gravidez independeu da idade ou mesmo escolaridade dos pais.

Todas as reações citadas nos parecem compreensiveis, frente a uma notícia geralmente inesperada. Pode surgir, então, insegurança, percebida no relato das adolescentes acerca da reação do pai frente a gravidez, pois frases como "e agora, o que nóis vamo fazê?", ou "... como agora a gente vai fazer?", ocorreram. Por isso, muitas vezes, os casais precisam de um tempo para decidir o que realmente desejam. Independentemente da reação inicial, a gravidez foi um acontecimento marcante, talvez por ser, potencialmente, fator desencadeante de mudanças na vida dos pais, inclusive na relação entre eles.

Quanto ao relacionamento no periodo de gravidez, algumas entrevistadas referiram que inexistiu; a maioria, entretanto, disse ter sido bom: "ele tinha muito cuidado comigo ", ou "... eu não tinha o que reclamar dele" e outras, ainda, apontaram que momentos bons e ruins se alternavam: "... tinha as duas coisas, coisas boas e ruins" ou "... tinha dia que brigava, tinha dia que tava bom", o que, nos parece, pode ser facilmente compreendido, já que se trata de relação entre duas pessoas, muitas vezes ambas adolescentes.

Ressaltamos que, quando da investigação acerca da participação dos pais nas consultas pré-natais, em geral, aparece a preocupação com o bebê: " (ele) perguntava se tava tudo bem com o nenê"; " (ele) perguntava se a nenê tava bem...ele sempre se interessou pela criança". Entretanto, a preocupação com a mãe, algumas vezes, também esteve presente: "... ele perguntava pro médico se tinha algum problema, se tava tudo bem escutar.

bebê também foi relatada: " ele ficou emocionado de 
com o neném, comigo, se ia ter algum problema no parto...". A emoção dos pais ao escutarem as batidas do coração do

o coraçãozinho da criança'; "ah, ele ouvia o coração do nenê e começava a dispencar a chorar".

Embora muitas adolescentes tenham referido que os pais as acompanhavam às consultas pré-natais, muitos deles não entravam no consultório, de acordo com o relato das mães, por vergonha ou por proibição do serviço de saúde. Ressaltamos a distorção que isso representa, no momento em que se discute a importância de incentivar a participação paterna, bem como a humanização do cuidado em todos os seus niveis. Além disso, tal proibição reforça a idéia de que os serviços não incluem os pais nos programas de educação perinatal. Assim, embora a participação efetiva dos pais seja apontada como um dos fatores que contribui com a diminuição dos problemas relativos à gravidez na adolescência, esta não tem sido viabilizada.

A participação dos pais durante a gestação se deu não apenas pelo acompanhamento durante as consultas pré-natais. Envolvimento emocional e/ou financeiro foram relatados: "ele colocava a mão na barriga e ficava falando com ele... perguntava o que eu tinha vontade, ia lá e comprava"; "ele me dava apoio, sempre estava junto comigo"; "é, ajudava de custo, o que eu precisava comprar pro nené... ele ajudava, mas emocionalmente, que seria o principal, ele não ajudou"; outras vezes, a ausência do pai foi citada: "ah, ele não participava muito não, ele ficava correndo atrás de serviço, de negócio".

Pudemos perceber pelas falas das adolescentes, que a impossibilidade de apoiar financeiramente era prontamente compreendida por elas, ao passo que o desinteresse, as ausências do pai, a falta de apoio emocional, enfim, não. Neste estudo, os pais com mais idade mantinham sempre um envolvimento financeiro, independentemente do oferecimento ou não de apoio emocional.

\section{Valorizando a Presença e Participação Companheiro/Pai}

A grande maioria dos pais compareceu à maternidade durante a internação das adolescentes para o parto, sendo que suas reações frente a tal situação foram variadas. $\mathrm{Na}$ percepção das adolescentes, eles demonstraram preocupação e nervosismo: "ele ficou um pouco nervoso... ", "... (eu) estava sentindo as dores, ele ficou desesperado, não sabia o que fazia", "...ele ficou lá, sem cor, desesperado" e carinho e segurança: " o tempo inteiro ele queria saber se eu precisava de alguma coisa... ", "eu me senti segura com ele estando ao meu lado". Enfim, nenhuma adolescente falou negativamente acerca deste momento, apesar de, para os pais, ter sido um momento de preocupação com a saúde da mãe e de seu filho.

Investigamos, também, o primeiro contato do pai com o bebê após o parto. Pudemos identificar, pelas falas das mães, reações de identificação: "...(ele) falou que era a cara dele", e, principalmente, de emoção e felicidade: " (ele) ficou emocionado, né...falou que não acreditava que era filho dele", "ele ficou bem feliz, pegou ela no colo, queria trocar ela... ", "ele achava ela bonita e começou a chorar", "...ele encheu o olho d'água, ele ficou emocionado", "ele pegou a criança e começou a dar risada... ". O envolvimento e a emoção dos pais ficam evidentes nestas falas e, certamente, comoveram também as mães e os aproximaram. Assim, novamente abordando a humanização da assistência ao parto, é importante destacarmos a necessidade dos serviços de saúde elaborarem normas e rotinas que facilitem e viabilizem a participação paterna.

Mesmo entre os pais que, num primeiro momento, haviam rejeitado a gravidez, pudemos observar mudança de atitude: "depois que o nenê nasceu mudou tudo... (ele) fica praticamente o tempo todo com o nenê" ou mesmo: " desde quando ele viu ela, ele nunca mais deixou de ver ela".

Destacamos que o nascimento do bebê, muitas vezes, foi apontado pelas adolescentes como marco, à partir do qual os pais tornaram-se mais participativos, às vezes as surpreendendo: "ele me surpreendeu bastante...no cuidar dela", "...tudo que ele tem ele divide", "...ele cuida do nené pra mim... (ele) é tudo que eu esperava que ele fosse" e "(ele) está sempre presente". Além disso, refletiu, também, em uma melhora no relacionamento: "ah, (ele) mudou um pouco sim...agora tá um pouquinho mais melhor...ele dá atenção pras duas, mais um pouquinho pra ela", "hoje (o relacionamento) é bem melhor, hoje nós somos super amigos ".

Estes dados estão de acordo, quando se descreve que a proximidade do relacionamento da mãe adolescente com o pai da criança, apesar de existir durante a gravidez, torna-se maior com o nascimento do bebê(10).

A participação do pai após o parto foi, freqüentemente, referida pelas mães, tanto com relação ao cuidado propriamente dito, quanto com relação aos aspectos financeiros da criação: "o menino fica doente $e$ precisa levá ao médico, ele vai junto comigo...ele cuida do menino também, ele troca... ", "(ele) comprava sempre uma coisinha prá ela, ele nunca deixava de lado, nem eu nem ela", "ele troca (a nenê), fica com ela... ", "...ele chega, agrada ela, carrega, vai passeá com ela... ", "... ele me dá dinheiro pra comprar as coisas pra ela... ".

Nas últimas décadas, observou-se uma mudança, ao integrar o pai como elemento de importância no processo gestacional. Por outro lado, percebe-se a existência de um maior interesse paterno em participar como companheiro, proporcionando conforto, segurança e desmistificando, dessa forma, sua participação exclusiva como provedor(16)

Assim, a categoria "Ele está sempre presente" emergiu da fala das adolescentes entrevistadas quanto a sua percepção acerca do pai do seu filho. Porém, não podemos deixar de citar que. ao término da entrevista, 
quando incentivamos as adolescentes a falarem livremente, apareceram sentimentos negativos, como mágoa do namorado: "...eu sente falta .. eu queria a companhia dele... mas eu tenho prazer em ter ela, eu me orgulho por ter assumido ela". Entretanto, também surgiram, e mais freqüentemente, sentimentos positivos, como de valorização da união e responsabilidade dos pais: "acho interessante assim, né, ser unido nós dois com ela, criá junto... sabe da vida dela inteira, até ela pegá uma idade que dê pra entender, né" e, principalmente, de satisfação referente ao namorado ou marido: "... a participação dele foi muito boa, não esperava... ", "de fato, eu sou muito novinha pra ter nenê, mas eu não me arrependo não, eu sou muito feliz com o meu marido, tô sempre com ele do meu lado ".

Em sintese, pelo relato das entrevistadas, pudemos observar três situações distintas: pais que de imediato aceitaram a gravidez, participando efetivamente desta fase, do momento do parto e da criação do filho; pais que, num primeiro momento, rejeitaram a gravidez mas que, após o parto, voltaram a procurar a adolescente e passaram a participar da criação dos seus filhos e pais que de imediato rejeitaram a gravidez, afastando-se das adolescentes de forma permanente, sendo, este último grupo de pais, bastante reduzido.

\section{CONSIDERAÇÕES FINAIS}

A participação paterna na gravidez de adolescentes ainda é pouco discutida, apesar dos estudos acerca da gestação nesta faixa etária abordarem, exaustivamente, os problemas sociais dela decorrentes, apontando a ausência do pai como um deles.

Assim, consideramos importante termos realizado esta pesquisa, a qual nos permitiu conhecer, através de um grupo de adolescentes, sua visão acerca da participação do pai durante sua gravidez, parto e na criação de seu filho.

Pudemos identificar, nas falas das jovens mães entrevistadas, que a dificuldade ou impossibilidade do pai contribuir financeiramente durante a gravidez ou criação do filho foi entendida e aceita, ao passo que a ausência, o não envolvimento, enfim, a falta de apoio emocional, não.

Apesar de não ter sido foco do nosso estudo, devemos citar o importante papel de apoio que as familias da adolescente e do pai do bebê, sob o ponto de vista das adolescentes, desempenharam, fato que pode ser percebido em diferentes momentos das entrevistas.

É importante ressaltarmos, ainda, a necessidade dos serviços de atendimento às gestantes elaborarem programas que facilitem e viabilizem a participação paterna nesse processo que é de ambos, e não apenas da mãe.

Finalizando, para que possamos conhecer de forma mais ampla a participação paterna na gravidez de adolescentes, consideramos necessário o desenvolvimento de outras pesquisas na área, especialmente aquelas cujos dados sejam obtidos dos próprios pais.

\section{REFERÊNCIAS BIBLIOGRÁFICAS}

(1) Pinto RP Azevedo CM. A gravidez na adolescência na perspectiva dos profissionais de saúde. In: Barrozo C. Gravidez na adolescência. Brasilia: IPLAN/ IPEA/ UNICEF; 1986. p.5782.

(2) Taquete SR. Sexo e gravidez na adolescência: estudo de antecedentes bio-psico-sociais. J Pediatr 1992; 68:135-9.

(3) Gauderer EC. Adolescência, os jovens e nós: uma visão pessoal: um ser esquisito ( $2^{\circ}$ parte). J Pediatr 1986; 61: 132-50.

(4) Viçosa G. Atendimento em grupo a gestantes adolescentes e seus companheiros: uma experiência de 10 anos. Rev Psiquiatr 1993; 15:65-9.

(5) Harris JLJ. Urban african american adolescent parents: their perceptions of sex, love, intimacy, pregnancy and parenting. Adolescence 1998; 33:833-44.

(6) Maia Filho NL, Mathias L, Tedesco RP, Cesáreo MA, Porta RMP. Gravidez entre adolescentes precoces: um evitável problema social. J Bras Ginecol 1994; 104: 363-7.

(7) Organizacion Mundial de la Salud. La salud de los jóvenes: un reto y una esperanza. Genebra: OMS; 1995.

(8) Munitz M, Silber T. El embarazo entre adolescentes. In: Lopes G. Salud reproductiva en las Americas. Washington: OPS/ OMS; 1992. p.96-131.

(9) Santos ES, Luz AMH, Mendes SMA, Agostini SMM. Maternidade e adolescência: sentimentos e atitudes. Rev Gaúcha Enferm 1987; 8:27-45.

(10) Bloom KC. Perceived relationship with the father of the baby and maternal attachment in adolescents. $\mathrm{J}$ Obstet Gynecol Neonatal Nurs 1998; 27:420 - 30.

(11) Minayo MCS. O desafio do conhecimento: pesquisa qualitativa em saúde. São Paulo: HUCITEC/ABRASCO; 1992.

(12) Lefèvre F, Lefèvre AMC, Teixeira JJV. O discurso do sujeito coletivo: uma abordagem metodológica em pesquisa qualitativa. Caxias do Sul: EDUCS; 2000.

(13) Haguette TMF. Metodologias qualitativas na sociologia. Rio de Janeiro: Vozes; 1997.

(14) Triviños ANS. Introdução a pesquisa em ciências sociais: a pesquisa qualitativa em educação. São Paulo: Atlas; 1992.

(15) Gomes R. A análise de dados em pesquisa qualitativa. In: Minayo MCS, organizador. Pesquisa social: teoria, método e criatividade. Rio de Janeiro: Vozes; 1994. p.67-80.

(16) Sabatino H, Cordeiro S, Rodriguez M, Sabatino LC. Avaliação psico-emotiva do casal grávido. Ver Ginecol Obstet 1994; 5:208-17.

\section{Artigo recebido em 10/08100 Artigo aprovado em 07/12/01}

